\title{
LETRAMENTO EM SAÚDE E NÍVEIS DE ESTRESSE COMO FATORES IMPACTANTES NA ADESÃO AO TRATAMENTO MEDICAMENTOSO E CONTROLE GLICÊMICO DE PACIENTES COM DIABETES MELLITUS TIPO 1
}

\author{
Camila Thais de Carvalho Messora \\ (Enfermeira, mestre em Ciências pela Faculdade de Ciências Médicas, \\ Universidade Estadual de Campinas) \\ camilamessora@gmail.com
}

INTRODUÇÃO: Letramento em Saúde (LS) corresponde a "competências cognitivas e sociais que determinam a motivação e a capacidade dos indivíduos para obterem acesso, compreenderem e utilizarem a informação em meios que promovam e mantenham uma boa saúde". No diabetes mellitus tipo 1 (DM1), 0 paciente deve entender e converter as orientações fornecidas em decisões que promovam o autogerenciamento adequado da sua doença. A adesão ao tratamento medicamentoso (ATM) é crucial no tratamento do DM1, e se adequada, pode diminuir os riscos de complicações agudas e crônicas da doença. O estresse relacionado ao diabetes, diabetes distress (DD), é comum em pacientes DM1 e diz respeito a sentimentos de tristeza, frustração, raiva, desapontamento, fadiga, desorganização e burnout. OBJETIVO: o objetivo deste estudo foi avaliar os níveis de LS e DD em pacientes DM1 e o possível impacto destes fatores na ATM e controle glicêmico. MÉTODOS: estudo transversal realizado em ambulatório especializado de um hospital universitário no sudeste do Brasil entre março de 2015 e dezembro de 2017, com 111 pacientes DM1 acompanhados há pelo menos seis meses no serviço. Foram coletados dados sobre condições sociodemográficas, econômicas e clínicas e aplicados os instrumentos: Test of Functional Health Literacy in Adults - Short version (S-TOFHLA) para avaliar LS; Problem Areas in Diabetes (PAID) para DD e Brief Medication Questionnaire (BMQ), para ATM. Estudo aprovado pelo CEP da UNICAMP sob o parecer de número 1.546.255. RESULTADOS: as prevalências de LS e ATM adequados e DD elevado foram, respectivamente, $86,49 \%, 53,15 \%$ e $49,55 \%$. Houve associação entre o maior tempo de estudo e LS adequado ( $p<.0001)$. A não ATM relacionou-se significativamente com estado civil - casado ( $p=0,0187$; OR: 2,770; IC: 1,185-6,452), com HAS ( $p=0,0102$; OR: 3,281 ; IC: 1,326-8,120) e maiores escores de PAID na subdimensão - problemas 
alimentares ( $p=0,0239$; OR: 1,155 ; IC: $1,019-1,310)$. O escore total PAID (DD) apresentou associação com maiores valores de glicemia capilar ao momento da entrevista $(p=0,0115)$, presença de neuropatia periférica $(p=0,0053)$ e uso do esquema de insulina NPH e insulina análoga ultrarrápida ( $p=0,0345)$. Não houve associação significativa entre LS e DD e os níveis de $\mathrm{HbA1c}$, exceto na subdimensão do PAID - problemas alimentares ( $p=0,0278)$. CONCLUSÃO: o LS foi adequado na maioria dos pacientes DM1 e os níveis de DD foram elevados em quase metade deles; entretanto, ambos, LS e DD, não impactaram no controle glicêmico e na ATM.

Palavras-chave: Diabetes Mellitus tipo 1. Letramento em saúde. Adesão ao tratamento medicamentoso. 